\section{INVENTARIO HISTÓRICO DE DESASTRES EN COSTA RICA EN EL PERIODO 1970-2020}

\author{
Ricardo A. Orozco-Montoya ${ }^{1^{*}}$, Alice Brenes-Maykall ${ }^{2}$ y Rebeca Sura-Fonseca ${ }^{3}$
}

\section{RESUMEN}

Los desastres a nivel mundial se traducen en pérdidas humanas y económicas principalmente en los países de ingresos bajos y medios. Esto es relevante para la planificación y toma de decisiones, por lo que se evidencia la importancia de poseer información oportuna mediante bases de datos sobre pérdidas por desastres. DesInventar surge como una herramienta teórica y metodológica, recopila registros históricos de pérdidas y facilita el análisis y la representación espacial y temporal de amenazas, vulnerabilidades y riesgos retrospectiva y prospectivamente para la gestión del riesgo y del desarrollo. En Costa Rica, este inventario se mantiene activo con datos desde 1970 hasta la actualidad. Es una base de datos en línea y de libre acceso. El artículo propone caracterizar las tendencias y comportamientos de los desastres en Costa Rica durante el periodo 1970-2020 registrados en DesInventar. Del total de eventos registrados (19.016), el 80\% corresponde a eventos hidrometeorológicos, $13 \%$ a epidemias y eventos humano-tecnológicos y $7 \%$ a geológicos. Se registraron 1.555 personas fallecidas. El análisis temporal arroja tendencias al aumento en cantidad de eventos y en personas fallecidas. Esto podría relacionarse con un conteo más sistemático de los desastres y el aumento de eventos como consecuencia del cambio climático.

\section{PALABRAS CLAVES}

DesInventar, Inventario histórico, Desastres, Base de datos, Riesgo

\section{HISTORICAL INVENTORY OF DISASTERS IN COSTA RICA IN THE PERIOD 1970-2020}

\section{ABSTRACT}

Disasters worldwide result in human and economic losses mainly in low- and middle-income countries. This is relevant for planning and decision making, which is why it is important to have timely information through disaster loss databases. DesInventar emerges as a theoretical and methodological tool, compiles historical loss records, and facilitates the analysis and spatial and temporal representation of hazards, vulnerabilities, and risks retrospectively and prospectively for risk and development management. In Costa Rica, this inventory is active with data from 1970 to the present. Is an online and freely accessible database. The article proposes to characterise the trends and behaviour of disasters in Costa Rica during the period 1970-2020 recorded in DesInventar. Of the total number of events registered (19.016), 80\% correspond to hydrometeorological events, $13 \%$ to epidemics and human-technological events and $7 \%$ to geological events. A total of 1.555 deaths were recorded. The temporal analysis shows an upward trend in the number of events and in the number of people killed. This could be related to a more systematic counting of disasters and the increase of events because of climate change.

\section{KEYWORDS}

DesInventar, Historical inventory, Disasters, Database, Risk

\author{
1. Escuela de Ciencias \\ Geográficas, Universidad \\ Nacional, Heredia, Costa Rica. \\ 2. Vicerrectoría de Extensión, \\ Universidad Nacional, \\ Heredia, Costa Rica. \\ 3. Escuela de Sociología, \\ Universidad de Costa Rica, San \\ José, Costa Rica. \\ *Autor de correspondencia: \\ ricardo.orozco.montoya@una. \\ ac.cr \\ DOI: \\ https://doi.org/10.55467/ \\ reder.v6i1. 85
}

\section{RECIBIDO}

22 de febrero de 2021

\section{ACEPTADO}

22 de julio de 2021

\section{PUBLICADO}

1 de enero de 2022

\section{Formato cita}

Recomendada (APA): Orozco-Montoya, R.A., Brenes-Maykall, A. \& Sura-Fonseca, R. (2022). Inventario Histórico de Desastres en Costa Rica en el Periodo 19702020. Revista de Estudios Latinoamericanos sobre Reducción del Riesgo de Desastres REDER, 6(1), 6682. https://doi.org/10.55467/ reder.v6i1.85

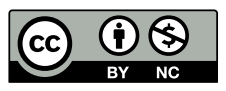

Todos los artículos publicados en REDER siguen una política de Acceso

Abierto y se respaldan en una Licencia CreativeCommons Atribución-NoComercial 4.0 Internacional.

Revista de Estudios Latinoamericanos sobre Reducción del Riesgo de Desastres (REDER)

Diseño: Lupe Bezzina 


\section{INTRODUCCIÓN}

Los efectos de desastres a nivel mundial son visibles y se traducen en pérdidas humanas y económicas en ascenso, en la mayoría de los casos. El Global Assessment Report on Disaster Risk Reduction (GAR) en su informe del 2019, destacó que más del $90 \%$ de la mortalidad atribuida a desastres comunicados internacionalmente, ha tenido lugar en países de ingresos medios y bajos; por ejemplo, de los 20 países en los que los desastres causaron una mayor cantidad de víctimas mortales en proporción con el tamaño de su población en el período 1990-2017, los 5 primeros eran países de bajos ingresos, y solo otros 5 se contaban entre los países de ingresos medios altos (UNDRR, 2019).

El Regional Assessment Report on Disaster Risk Reduction (RAR) para América Latina y el Caribe en su informe del 2021, destacó que entre 1998 y 2017, en la región se produjo el $53 \%$ de las pérdidas económicas mundiales por desastres asociados a amenazas de origen climático y el $46 \%$ de las pérdidas globales por desastres de la última década. En línea con lo anterior, la Oficina para la Coordinación de Asuntos Humanitarios (OCHA) de la ONU, indicó que en los últimos 20 años (2000-2019) los eventos de origen climático, y particularmente las inundaciones, son el tipo de amenaza más común en la región. Desde el 2000 se han producido 548 inundaciones que han afectado a casi 41 millones de personas y han dejado casi US\$26 mil millones en pérdidas económicas totales (OCHA, 2020).

De acuerdo con el Banco Mundial (2021), Costa Rica es un país de ingresos medios, y anualmente registra numerosos eventos hidrometeorológicos y de otra índole que ponen en riesgo a su población. De manera que, como parte de los acuerdos internacionales y las necesidades del país para gestionar estas emergencias, se han realizado esfuerzos por contar con información periódica sistematizada y de calidad relacionada con la frecuencia de desastres, sus características y efectos.

Específicamente, la base de datos DesInventar se presenta como un instrumento que recopila registros históricos nacionales para uso investigativo-científico, académico e institucional. Su objetivo es facilitar el análisis y la representación espacial y temporal de amenazas, vulnerabilidades y riesgos de manera retrospectiva y prospectiva para aplicaciones de gestión del riesgo, a través de acciones de reducción de riesgo, desde las de planificación y mitigación, hasta las de preparativos y atención y recuperación post desastres. Finalmente, se persigue incidir en la gestión del desarrollo. Esta herramienta, se concibe como un método sencillo y homogéneo para recopilar, almacenar, analizar y mostrar datos relativos a las pérdidas que producen los desastres, evidenciando el impacto de los pequeños, medianos y grandes desastres.

En ese sentido, tomando el contexto mundial de desastres y las preocupaciones internacionales por reforzar la gestión del riesgo ante el inminente cambio climático, este artículo se propone caracterizar las tendencias y comportamientos de los desastres en Costa Rica durante el periodo 1970 al 2020 registrados en la base de datos de daños y pérdidas por desastres DesInventar. Al mismo tiempo, se pretende dar difusión a dicha base de datos.

\section{CONTEXTO MUNDIAL Y REGIONAL DE LOS DESASTRES}

En los últimos dos decenios, los fenómenos geológicos de gran magnitud han seguido incidiendo en las cifras de mortalidad, ya que a ellos puede atribuirse el $51 \%$ de la mortalidad en todo el mundo, seguido por los eventos de tipo hidrometeorológico con un 30\% aproximadamente. Precisamente, los desastres asociados con amenazas naturales obligaron a desplazar en promedio, a 23,9 millones de personas cada año entre el 2008 y el 2018 (Irish Red Cross, 2018). Según la Red de Vigilancia y Protección de los Repatriados del ACNUR, del total de desplazamientos internos ocurridos en el 2018, el 32\% se atribuyó a inundaciones y el 29\% a sequías (UNDRR, 2019).

Por otro lado, las pérdidas económicas totales aumentaron de modo considerable entre 1980 y 2017, elevándose en promedio entre US\$250 mil millones y US\$ 300 mil millones al año, siendo mayores en países de ingresos bajos y medios (UNDRR, 2019). Las amenazas hidrometeorológicas son las que causan la mayor parte de las pérdidas económicas. Las inundaciones son las más costosas, dado que ocasionan el $30 \%$ del total de las pérdidas, seguidas por los fenómenos multiamenaza y por los terremotos (12\%).

Geográficamente, Asia sufrió el $42 \%$ de las pérdidas económicas totales que se registraron a nivel global entre 2005 y 2017, el continente americano el 40\%, no obstante, Asia solo concentró el 
$23 \%$ de los eventos en el mismo periodo mientras que América el $4 \%$ con el $12 \%$ de los fallecimientos y desapariciones de personas, debajo de Asia con el 70\% y África con el 17\% (UNDRR, 2019).

Lo anterior, pone en evidencia que el continente americano es una de las regiones con mayor problemática a desastres a nivel mundial. Específicamente, en América Latina y el Caribe, el promedio anual de personas afectadas directa e indirectamente ha crecido de forma acelerada. En los últimos 20 años (2000-2019), 152 millones de personas han sido afectadas a causa de 1205 desastres en la región, con pérdidas económicas alrededor de US\$142 mil millones (OCHA, 2020).

Entre 1997 y 2017, 1 de cada 4 desastres registrados en el mundo ocurrió en América Latina y el Caribe, 9 de cada 10 personas perjudicadas por desastres en la región se vieron afectadas por eventos de origen climático (principalmente inundaciones) y 7 de cada 10 murieron por eventos de origen geológico (sobre todo sismos) (UNDRR, 2021a).

Más recientemente, durante el 2020, según el Annual Report 2020: Weather, Climate \& Catastrophe Insight, las pérdidas económicas en América Latina y el Caribe estuvieron lideradas por los huracanes Eta e lota, cuando se registraron pérdidas por más más de US\$ 6,800 millones en Centroamérica (Eta) y US\$1,3 mil millones adicionales en pérdidas totales para toda la región (lota). No obstante, las pérdidas económicas totales fueron un $22 \%$ más bajas que el promedio entre el 2000-2019 (US\$ 26 mil millones), pero un 22\% más altas en comparación con la mediana del siglo XXI (US\$ 17 mil millones) (Aon, 2021).

Estas pérdidas por desastres han impactado particularmente a las economías más pequeñas de la región. Mientras que en los países grandes el promedio anual de pérdidas puede representar menos del $1 \%$ del Producto Interno Bruto (PIB), en los países pequeños ha llegado a ser muy superior. En algunos casos, estas pérdidas llegan a representar el $100 \%$ del PIB anual (UNDRR, 2021a).

El contexto explicado anteriormente, pone en evidencia la importancia y necesidad de contar con información oportuna y pertinente, que arroje datos y análisis certeros y comparativos para su uso en balances, en líneas de base, en investigación y sobre todo en los procesos para la toma de decisiones enfocados en la planificación del desarrollo y su presupuestación; de ahí, la relevancia de crear, mantener y mejorar sistemáticamente las bases de datos sobre pérdidas que producen los desastres a nivel nacional, regional y global.

Con base en la resolución número 44/236 de la ONU sobre el "Decenio Internacional para la Reducción de los Desastres Naturales" a partir del 01 de enero de 1990 y bajo el objetivo de reducir la pérdida de vidas, los daños materiales y los trastornos sociales y económicos causados por los desastres (especialmente en los países en desarrollo), un grupo de profesionales con un enfoque social, dedicados a la promoción y estudio de los desastres en América Latina y el Caribe, constituyeron La Red de Estudios Sociales en Prevención de Desastres en América Latina, conocida como La Red (La Red, 1992), que elaboró una agenda de investigación en los temas más relevantes expuestos en la declaratoria de la ONU.

Uno de los principales hallazgos de La Red fue lograr visibilizar la carencia de información sobre pérdidas por desastres en la región que evidenciara el impacto no solo de grandes desastres, sino de pequeños y medianos que ocurren en la cotidianidad y de los cuales no se tenía registro. Además, dispersión de información y poca continuidad en las bases de datos nacionales. La posibilidad de hacer análisis comparativo entre países se veía comprometido por la falta de homogeneidad de las bases de datos disponibles o por el limitado alcance de las variables disponibles.

Hasta ese momento, solo se contaba con bases de datos globales como The International Disasters Database (EM-DAT) del Centre for Research on the Epidemiology of Disasters (CRED) de la Universidad Católica de Louvain (UCLouvain) en Bélgica (CRED, 2018). Sin embargo, los umbrales que aplica EM-DAT para determinar qué constituye un desastre (al menos 10 personas fallecidas, 100 afectados, declaración del estado de emergencia y petición de ayuda internacional) hacen que no se tengan en cuenta los desastres a pequeña y mediana escala. Esta diferencia puede ser considerable, sobre todo en el caso de aquellos países que no están expuestos a fenómenos peligrosos a gran escala (UNDRR, 2019).

A finales de 1993, La Red lideró el proyecto titulado Inventarios de Desastres en América Latina, el cual en su fase piloto discutió criterios conceptuales y metodológicos sobre el tratamiento 
analítico de los desastres, vistos a diversos niveles de resolución espacial; y acopiar la información sobre estos en el periodo 1990-1999, en fuentes disponibles, en una muestra de 8 países latinoamericanos, con la finalidad de desarrollar un instrumento de sistemas a partir de la revisión de fuentes hemerográficas inicialmente. Esto consolidó la agenda de investigación y retos teóricos, conceptuales y metodológicos, siendo el origen de la base de datos DesInventar.

A partir del 2018, inició su funcionamiento DesInventar Sendai, la herramienta en línea específica para recopilar datos sobre las pérdidas y los daños causados por los desastres, la cual tiene como origen las bases de datos de DesInventar formuladas por La Red. Se migraron las bases de datos existentes del sistema anterior al nuevo repositorio público de la UNDRR para, así, cumplir las exigencias del grupo de trabajo intergubernamental de expertos de composición abierta del Marco de Acción de Sendai (2015-2030) para la reducción del riesgo de desastres. Este sistema mejorado emplea definiciones de las amenazas y los efectos armonizadas con el Marco de Sendai y sus indicadores.

Además, es importante indicar que DesInventar Sendai al tener como base a DesInventar, sigue su misma metodología y análisis al recabar datos detallados sobre las pérdidas y los daños generados por desastres a todas las escalas (temporales y espaciales) gracias al empleo de metodologías comunes (UNDRR, 2019).

Debido al grado de detalle que aporta este tipo de datos, resulta posible registrar las pérdidas derivadas de una serie de fenómenos recurrentes a pequeña y mediana escala que producen y acumulan daños, lo que permite calcular lo que se conoce como "riesgo extensivo". Estos desastres a pequeña y mediana escala suelen excluirse de las bases de datos globales sobre desastres, pero pueden tener consecuencias corrosivas para las vidas y los medios de subsistencia, sobre todo en las comunidades más pobres y vulnerables (UNDRR, 2019).

Concebidos los desastres como la materialización de un riesgo o como un riesgo manifiesto, Lavell y Lavell (2010) definen el riesgo extensivo como aquellos pequeños y medianos eventos que acumulativamente suman una gran parte de las pérdidas económicas sobre periodos largos de tiempo; y a los intensivos, como los grandes eventos en los cuales se concentran las grandes pérdidas económicas y disrupciones de vida en momentos únicos.

Es en este contexto donde Deslnventar, como base de datos de sistematización, obtiene mayor relevancia, y su valioso aporte se hace ver globalmente con su migración hacia DesInventar Sendai, como la única base de datos con información que permite la medición de los indicadores de las metas del Marco de Acción de Sendai, lo que consolida los datos anuales que se comunican a través del Monitor. DesInventar Sendai puede generar estas cifras o transferir esta información automáticamente, por vía electrónica, a las metas mundiales del Monitor del Marco de Sendai (UNDRR, 2019).

No obstante, existe un trabajo previo y arduo que emprendió La Red desde la concepción de Deslnventar en la década del 90 y que posibilita su uso actual para medir los indicadores de las metas del Marco de Sendai. Este trabajo para América Latina y el Caribe significó la actualización constante de las bases de datos nacionales, a través de la coordinación, guía y mantenimiento realizado por la Corporación Observatorio Sismológico del Sur-Occidente (OSSO) de Colombia desde 1994 y que hasta la actualidad colabora en los procesos de migración de las bases de datos de América Latina y el Caribe a DesInventar Sendai.

En Costa Rica, DesInventar inició en el Programa de Estudios Sociales en Desastres de la Secretaría General de la Facultad de Ciencias Sociales (SG-FLACSO). Los primeros años que se registran fueron para el periodo 1980-1998. A través de sinergias y esfuerzos conjuntos, se amplió la base de datos alojada en FLACSO y se incluyó el periodo 1970-1979 en el marco de un proyecto. A partir del 2011 y hasta la actualidad, la academia ha logrado mantener la base de datos actualizada a través de una actividad académica del Programa Institucional de Gestión del Riesgo de Desastre (PIGRD) de la Vicerrectoría de Extensión de la Universidad Nacional (UNA) de Costa Rica. Actualmente la base de datos posee un total de 19.016 registros de eventos ocurridos en el país en el periodo 1970-2020. 


\section{DATOS Y METODOLOGÍA}

\section{Fuente de datos}

Como se mencionó en el objetivo de este artículo, se utilizó la base de datos de desastres DesInventar Costa Rica (DI-Costa Rica) de los eventos ocurridos en el periodo 1970-2020. Dicha herramienta toma en cuenta 19.016 fichas registradas en la base de datos en este periodo.

Es importante indicar que, las fuentes de información de la base DI-Costa Rica se fundamentan en fuentes hemerográficas, principalmente los registros de los años más antiguos. De forma gradual, hacia los años actuales, se diversificaron las fuentes de información, incluyendo informes técnicos de instituciones estatales y centros de investigación dedicados a vigilar y monitorear eventos naturales (ver Figura 1).

En cuanto a la confiabilidad de la información que posee la base de datos, se destaca que cada registro requiere de un análisis riguroso en su incorporación, con el fin de reducir sesgos e información errónea, contrapuesta o repetitiva. No obstante, la identificación y el análisis de las causas de los desastres evidencian la complejidad del riesgo y la concatenación de los procesos naturales y sociales que se sobreponen dando origen al desastre.

El proceso de incorporación de la información en la base de datos se compone de 6 etapas (ver Figura 2), desde la búsqueda de la información y ubicación de las fuentes, hasta la aprobación de cada registro para su disposición, de manera libre, a las personas usuarias. A lo largo del proceso se requiere de un análisis detallado e investigativo, donde la persona sistematizadora se enfrenta a problemáticas ligadas a la comprensión del evento y sus posibles causas.
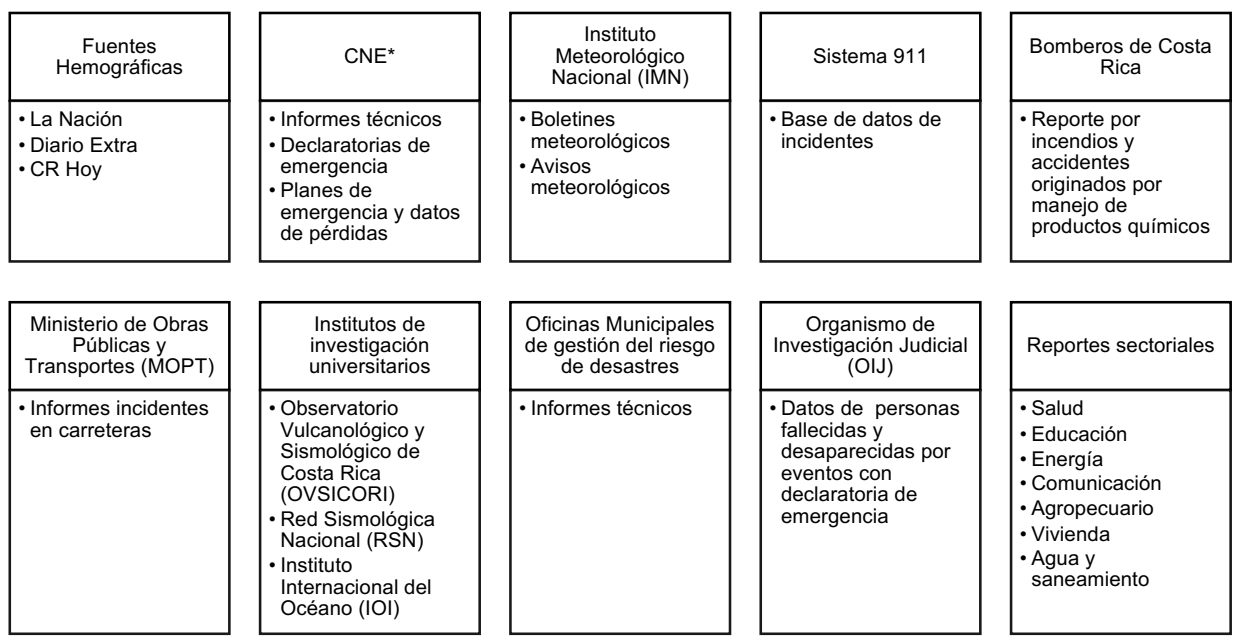

Figura 1. Fuentes de información de la base de datos DI-Costa Rica

Fuente: Autores, 2022

* Comisión Nacional de Prevención de Riesgos y Atención de Emergencias (CNE) de Costa Rica

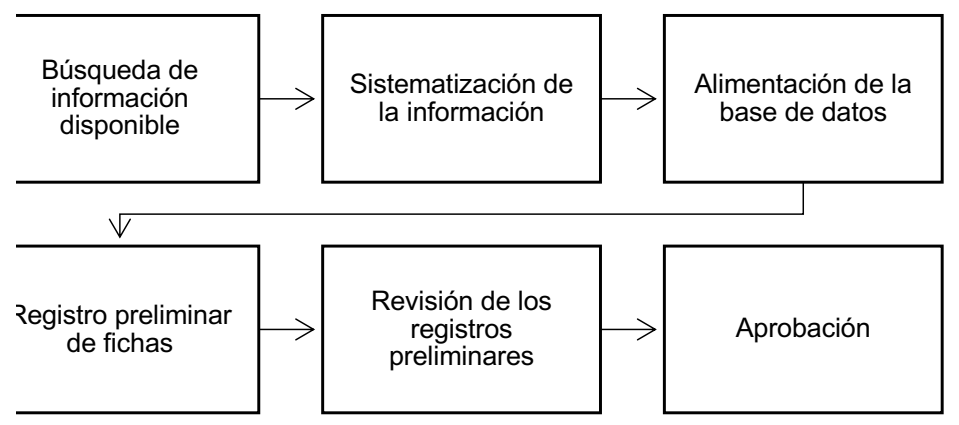

Figura 2. Proceso de incorporación de la información de la base de datos DI-Costa Rica Fuente: Autores, 2022

\section{Metodología}

Para cumplir el objetivo de este trabajo, inicialmente se mostró un resumen de la tipología de eventos que posee la base de datos en el periodo de estudio; para ello, se utilizaron 19.016 fichas registradas. En segunda instancia, se realizó un análisis descriptivo espacial y temporal de 
las fichas en el mismo periodo, exceptuando el evento "Epidemia" para este análisis, asociado con el SARS-CoV2.

El análisis espacial y temporal se enfocó en los eventos naturales de tipo hidrometeorológico y geológico. Se mostró la distribución espacial de los eventos y sus efectos en el territorio nacional. Este análisis se llevó a cabo siguiendo el registro que utiliza la base de datos según la división político-administrativa oficial del país en tres niveles geográficos: provincia, cantón y distrito (Decreto Ejecutivo $\mathrm{N}^{\circ}$ 40184-MGP, 2017). Para este caso el análisis espacial se elaboró a nivel de cantón y distrito, con cartografía representativa.

El análisis temporal se llevó a cabo mediante la generación de gráficos de las series de tiempo de diversas variables para el periodo 1970-2020 como: el número total de eventos registrados, número de inundaciones y deslizamientos, así como de muertos, heridos, entre otros. A la vez, como parte del análisis temporal se realizó un análisis de tendencia utilizando la prueba de Mann-Kendall y un análisis de medias de distintas variables por décadas. Esto permitió obtener resultados en cuanto al comportamiento actual de los eventos de desastre en Costa Rica.

El test de Mann-Kendall utilizado, corresponde a una prueba no paramétrica (Kendall, 1975; Mann, 1945), empleada comúnmente para estudios de tendencia en series de datos ambientales (Yu et al., 2007). Dicha prueba realiza una comparación en orden secuencial entre los valores que componen la serie temporal que se está analizando (Silva, 2007).

Los análisis realizados pretendieron dar a conocer de manera general las utilidades $e$ información que pueden obtenerse con la base de datos DI-Costa Rica para investigaciones científicas, así como algunas posibles relaciones entre variables que se obtienen desde DI-Costa Rica y que posibilitan estudios más detallados y específicos de un evento particular o de una situación o desastre específico ocurrido.

\section{RESULTADOS Y DISCUSIÓN}

Análisis descriptivo y espacial del inventario histórico de desastres de Costa Rica para el periodo $1970-2020$

Del total de eventos registrados en el periodo de análisis (19.016), aproximadamente el $80 \%$ corresponde a eventos de tipo hidrometeorológico, relacionados según el listado de eventos de DI-Costa Rica con inundación, lluvias, deslizamientos causados por condiciones atmosféricas, avenida torrencial, tempestad, vendaval, sequía y marejada (ver Figura 3). Los eventos de tipo geológico representan el $7 \%$ y corresponden a eventos de sismo y actividad volcánica, así como deslizamientos causados por sismos. El restante 13\% corresponde a eventos de otro tipo como epidemias y de tipo humano-tecnológico (incendios estructurales, explosión, escape, colapso estructural, contaminación y accidentes) (ver Figura 3).

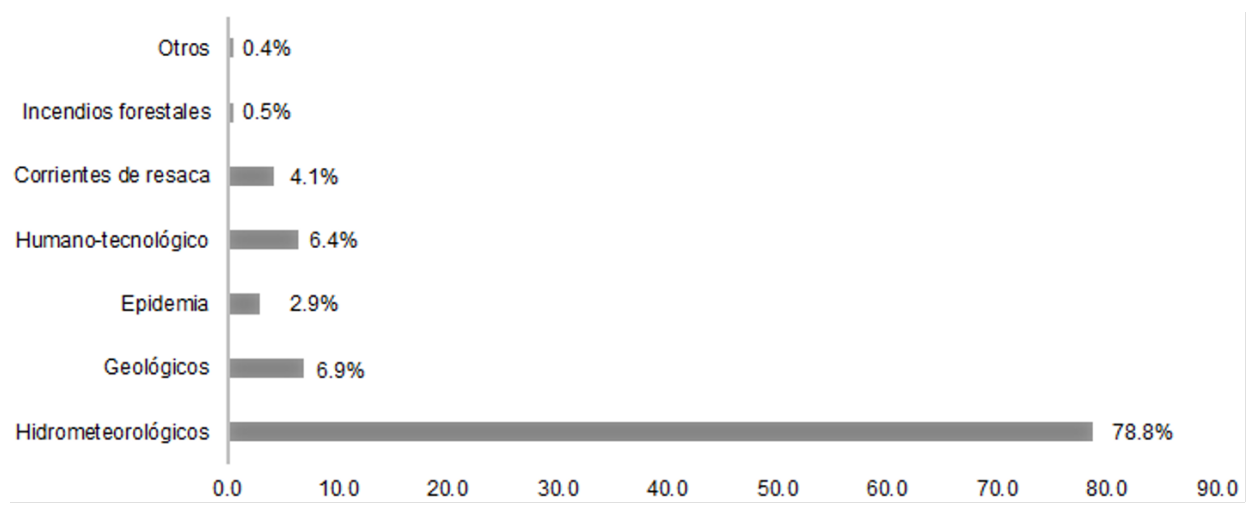

Figura 3. Cobertura de eventos por tipología en la base de datos DI-Costa Rica, periodo 1970-2020 Fuente: Autores, 2022, con datos de UNDRR (2021b)

En cuanto a la distribución espacial de los registros de eventos en el periodo de análisis, todos los distritos del país (488), a excepción de 3 , presentan algún registro. Aproximadamente la mitad de estos (258) concentra menos de 25 , el $40 \%$ registra entre 26 y 99 , mientras que casi el $10 \%$, compuesto por 37 distritos, concentra más de 100 registros. En este último caso, sobresalen 6 distritos con más de 200 registros, de los cuales, únicamente el distrito de Alajuela se ubica en el área metropolitana del país; los demás, corresponden a localidades urbanas en áreas costeras del país (Ver Figura 4). 
Al realizar un análisis de relación de variables entre la cantidad de eventos registrados por distrito y el Índice de Desarrollo Social Distrital (IDS) realizado por el Ministerio de Planificación y Política Económica (Mideplan) de Costa Rica para el 2017 (Mideplan, 2017), se obtuvo como resultado que, los distritos clasificados con bajo y muy bajo desarrollo relativo concentran el $40 \%$ de eventos registrados ( $29 \%$ y $11 \%$ respectivamente), entre ellos destacan Parrita, Corredor, Guaycará, Golfito y Siquirres. Los clasificados como medio concentran otro $40 \%$ y el restante $20 \%$ en los clasificados como alto. De los 37 distritos que registran más de 100 eventos, 11 son de desarrollo muy bajo, en orden por cantidad de eventos registrados: Matina, Puerto Viejo y Valle de la Estrella, y bajo: Parrita, Corredor, Guaycará, Golfito y Siquirres; 22 son de desarrollo medio: Limón, Quepos, Guápiles, Jacó y San Isidro de El General, entre otros; y 4 de alto: Alajuela, Desamparados, Heredia y Guadalupe (ver Figura 4).

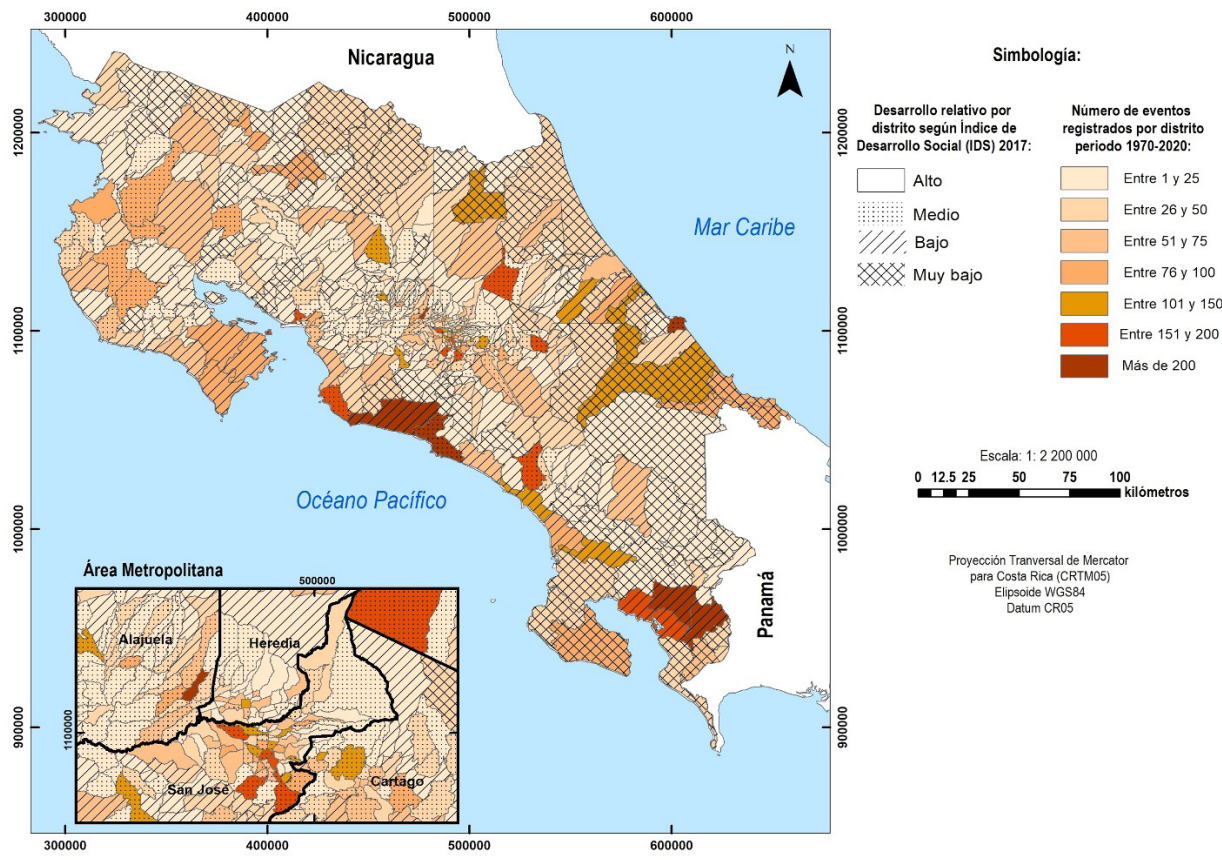

Figura 4. Relación entre IDS-Costa Rica y eventos registrados por distrito, Costa Rica, periodo 1970-2020 Fuente: Autores, 2022, con datos de UNDRR (2021b)

Respecto a la cantidad de personas fallecidas y desaparecidas atribuidas a los desastres y, tomando como referencia la primera y segunda meta mundial del Marco de Sendai para la Reducción del Riesgo de Desastres 2015-2030 -que establecen una reducción de la mortalidad mundial causada por desastres y una reducción del número de personas afectadas por desastres al 2030 respectivamente (UNDRR, 2017) -, en la Figura 5 se muestra la cantidad de personas fallecidas, heridas y desaparecidas por año y por tipo de evento para el periodo de análisis. Es importante destacar que se contabilizan 1.555 personas fallecidas, de las cuales la mitad corresponde a corrientes de resaca, el $32 \%$ a eventos de tipo hidrometeorológico (503 personas), el $11 \%$ a eventos de tipo humano-tecnológico (163 personas) y el $5 \%$ a eventos geológicos (83 personas).

Las corrientes de resaca (corriente fuerte de agua que fluye desde la costa hacia mar abierto que representan un peligro considerable para usuarios de playas a nivel global (Arozarena-Llopis \& Gutiérrez-Echeverría, 2016; Brighton et al., 2013; Gensini \& Ashley, 2010; Lizano, 2012)) se registran como la segunda causa de muerte violenta en el país entre el 2001 y 2012. En total se sumaron 1.391 ahogamientos, de los cuales 616 se produjeron en ambientes marino-costeros, siendo responsables de más muertes al año que las electrocuciones, asfixia, intoxicaciones, golpes o mordedura de animales (Arozarena-Llopis y Gutiérrez-Echeverría, 2016) ${ }^{1}$.

Por su parte, los eventos de tipo hidrometeorológico representan la segunda causa de muerte registrada en la base de datos, siendo los ligados a eventos extremos húmedos de precipitación los que registran la mayor cantidad de personas fallecidas (221 por deslizamiento, 129 por inundaciones y 81 por avenidas torrenciales). De acuerdo con Maldonado et al. (2018) y Taylor y Alfaro (2005), estos eventos son los que mayormente afectan al país y a la región Centroamericana
1. La base de datos DI-Costa Rica cuenta con esta información registrada para el periodo 2001-2018 basado en datos suministrados por el Programa Red de Observación del Nivel del Mar e Investigación de Amenazas Costeras (RONMAC) de la Universidad Nacional de Costa Rica, que a partir del 2020 pasa a llamarse Sistema Nacional de Monitoreo de Tsunamis (SINAMOT) (SINAMOT, 2021), además dicha información fue anteriormente validada por el Organismo de Investigación Judicial (OIJ) de Costa Rica. 
en general, y debido a su ocurrencia persistente de manera aislada o combinada genera daños físicos y pérdidas económicas recurrentes.

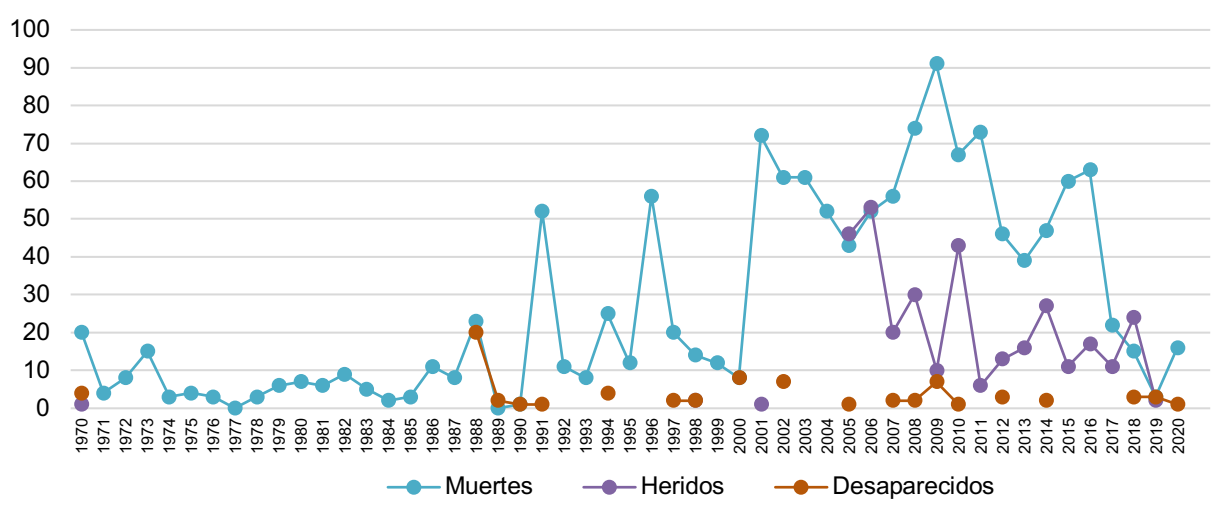

Figura 5. Número total de muertos, heridos y desaparecidos por desastres en Costa Rica por año (1970-2020*) Fuente: Autores, 2022, con datos de UNDRR (2021b)

* En el año 2020 se registraron 3.409 personas heridas por desastres (dato relacionado con personas enfermas por el virus SARS- $\mathrm{CoV}$-2). Este dato no se coloca en el gráfico para evitar que la escala del eje Y se extienda hasta perder la apreciación del comportamiento de las curvas en los otros años.

Al analizar estas cifras según su distribución territorial, se encuentra que el mayor número de personas fallecidas se registró en el cantón de Escazú: 26 , de las cuales 23 fueron resultado del deslizamiento en Calle Lajas a raíz de la tormenta tropical Thomas en 2010. El segundo foco de fallecimientos estuvo en la zona sur del país, concretamente en Osa, Corredores y Pérez Zeledón, reportándose 24,23 y 18 casos respectivamente, debido a inundaciones y avenidas torrenciales. Finalmente, destacan 20 muertes en el cantón central de San José por diversas causas.

La Figura 6 muestra el número de personas fallecidas y el número de eventos hidrometeorológicos por cantón para el periodo de análisis, donde sobresale que la mayor cantidad de cantones $(75 \%)$ poseen entre 51 y 300 fichas registradas por este tipo de eventos. Es importante resaltar que los cantones de Desamparados y San José, en el área metropolitana del país, cuentan con más de 750 fichas registradas, así como únicamente 3 cantones de la provincia de Alajuela (Río Cuarto, San Mateo y Orotina), ubicados fuera del área metropolitana, poseen menos de 50 fichas generadas por este tipo de eventos.

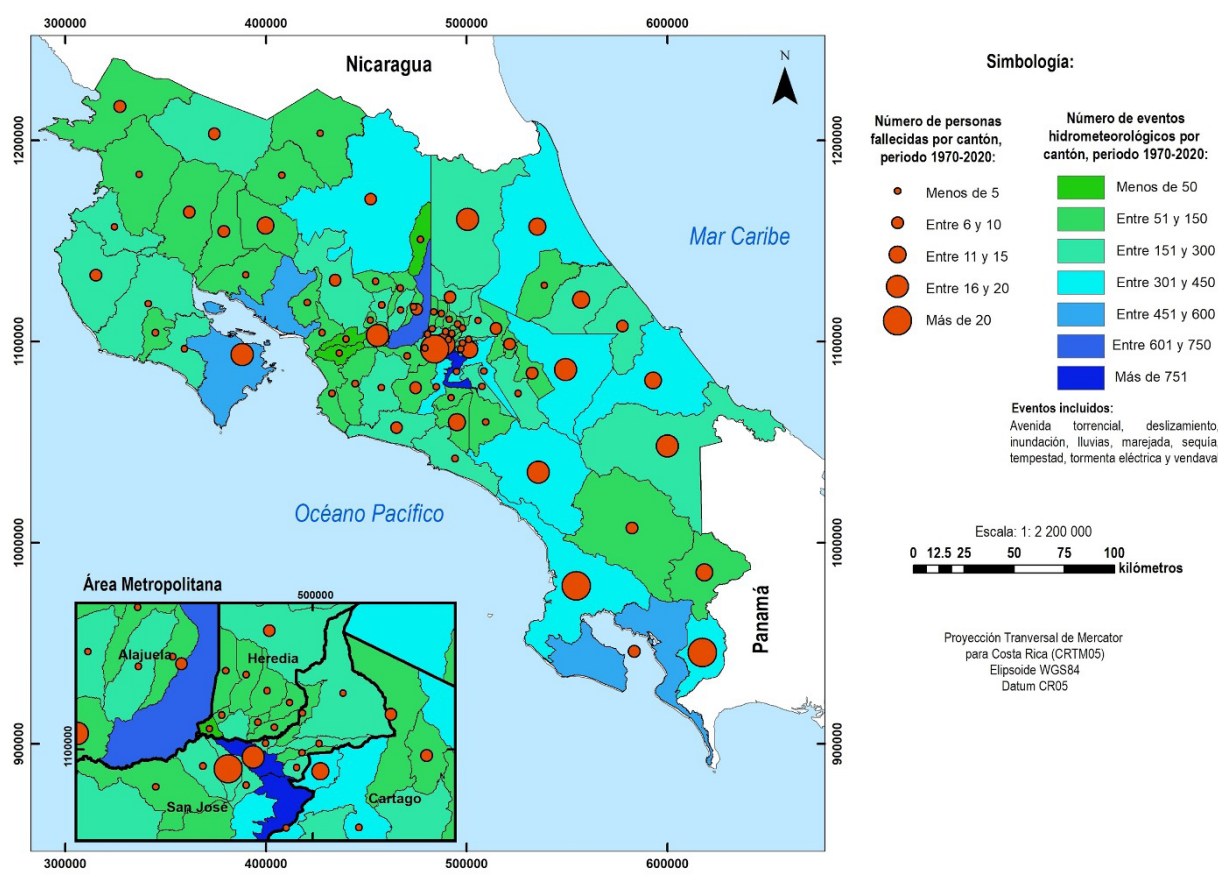

Figura 6. Número de fallecidos y de eventos hidrometeorológicos registrados por cantón, Costa Rica, período 1970-2020 Fuente: Autores, 2022, con datos de UNDRR (2021b) 
En cuanto a las pérdidas económicas causadas directamente por desastres, la tercera meta del Marco de Sendai (2015-2030) apunta a la reducción de éstas, por lo que al realizar un análisis de los registros en la base de datos, se constata que la misma posee información dispersa e incompleta para los sectores: vivienda, agropecuario, comunicación, acueducto y alcantarillado, industria, transporte, energía e infraestructura educativa y de salud. No obstante, es relevante señalar, como un esfuerzo desde la base DI-Costa Rica, que los registros de eventos de los últimos 15 años, y sobre todo los eventos que generaron declaratorias de emergencia por la Comisión Nacional de Prevención de Riesgos y Atención de Emergencias (CNE) de Costa Rica, poseen información de pérdidas por sector más detallada.

Un ejemplo de lo anterior puede comprobarse en la Figura 7, la cual analiza de manera espacial para el periodo de estudio, el número de viviendas destruidas por eventos de tipo geológico en el país (sismos, actividad volcánica y deslizamientos atribuidos a eventos geológicos), así como el número de este tipo de eventos naturales registrados por cantón en la base de datos.

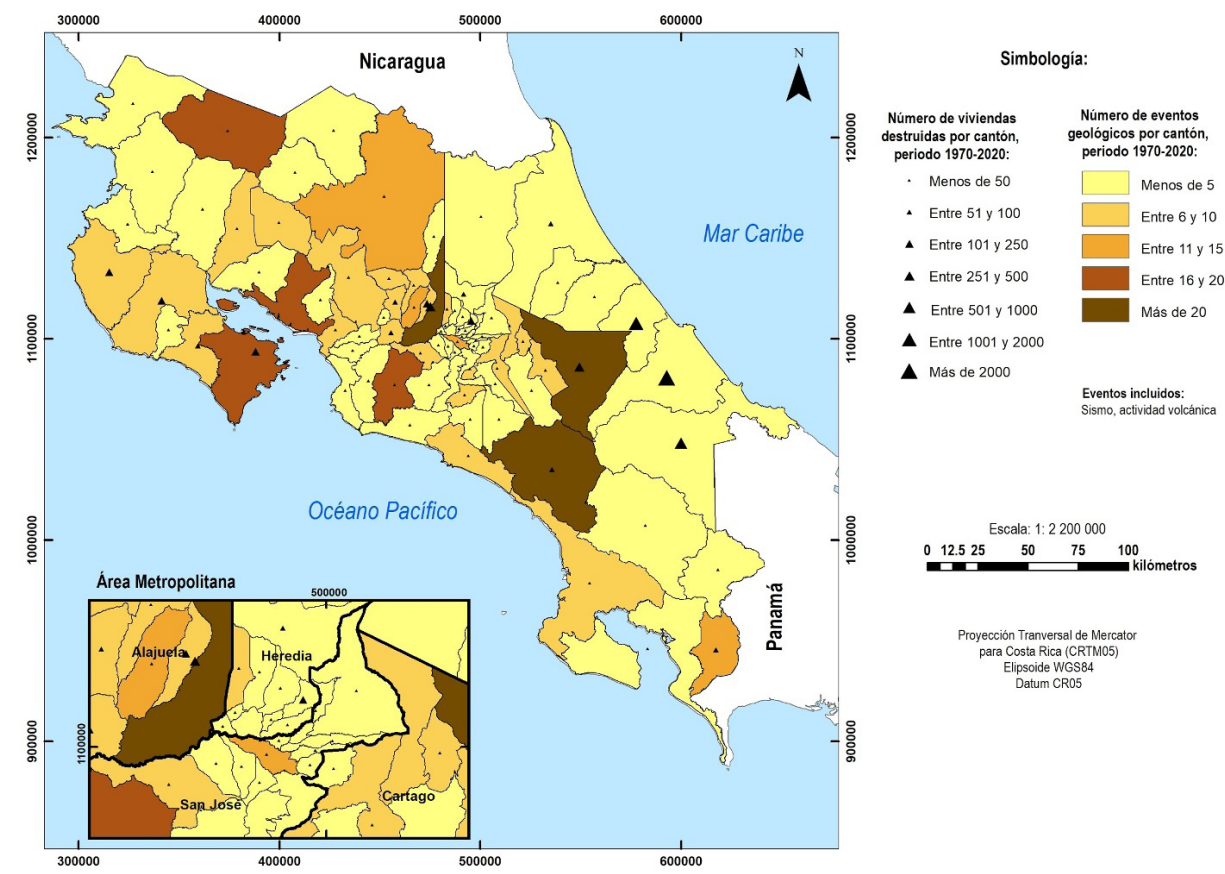

Figura 7. Número de viviendas destruidas y de eventos geológicos registrados por cantón, Costa Rica, periodo 1970-2020 Fuente: Autores, 2022, con datos de UNDRR (202lb)

Tomando como referencia que el sector vivienda es uno de los más afectados por desastres (Brenes y Orozco, 2021), se registran 10.362 edificaciones de este tipo destruidas entre 1970 y 2020. Las principales causas fueron los sismos (60\%), seguidos de los fenómenos hidrometeorológicos $(30 \%)$ y otros (10\%). Si se pone el foco en los primeros, se observa que 6 de cada 10 casas destruidas en el período bajo análisis se localizaban en la Vertiente del Caribe, específicamente en Limón, Matina y Talamanca. Lo anterior se explica por el terremoto que ocurrió en Limón en 1991, con una magnitud de Ms= 7.1, el cual ocasionó pérdidas equivalentes al $4,2 \%$ del PIB de ese año (Morales, 1994). Un ejercicio efectuado por Campos-Durán et al. (2021) determinó que, si se actualizan a valor presente (2020) los costos económicos generados por ese evento, el monto asciende a 3.433 millones de dólares.

\section{Análisis temporal del inventario histórico de desastres de Costa Rica para el periodo 1970-2020}

La base de datos de Desinventar presenta como una de sus principales utilidades el análisis temporal de la ocurrencia y frecuencia de los eventos según el registro realizado. Es así como, al realizar filtros de información por año, mes o día pueden enlazarse variables y obtenerse hallazgos que permiten comprender y analizar la relación entre causas y efectos en un momento determinado y su conexión en el tiempo con la ocurrencia de eventos específicos.

En el periodo de 51 años de análisis para Costa Rica hecho a partir de los registros de la base de datos, se obtuvo que, realizando un filtro a nivel mensual, se reconoce octubre como el 
que mayor cantidad de eventos registra, con 3.706, seguido por setiembre con 3.014 eventos (ver Figura 8), lo cual se relaciona con eventos extremos lluviosos en el país, ya que estos meses concentran el $40 \%$ de eventos hidrometeorológicos registrados en la base de datos. Esta situación ha sido analizada por Maldonado et al. (2018) y Retana (2012), quienes indican que los eventos extremos lluviosos en Costa Rica y la región Centroamericana se relacionan con la ocurrencia de sistemas de baja presión y el efecto indirecto de huracanes del Caribe, donde los primeros pueden presentarse desde enero hasta diciembre, siendo entre abril y noviembre el período de mayor probabilidad de aparición, y los huracanes tropicales se concentran entre junio y noviembre, siendo entre setiembre y noviembre cuando se da su mayor probabilidad de ocurrencia.

Además, junio y agosto sobresalen como el tercer y cuarto mes en concentrar la mayor cantidad de eventos en la base de datos, de los cuales el $80 \%$ corresponde a eventos de tipo hidrometeorológico (ver Figura 8), siendo junio y setiembre meses que representan máximos relativos en la ocurrencia de extremos lluviosos ligados a ciclones tropicales. Además, el trimestre agosto-setiembre-octubre (ASO), presenta la mayor probabilidad (70\%) de encontrar estos sistemas cerca de la costa (Alfaro y Quesada, 2010; Hidalgo et al., 2020; Taylor y Alfaro, 2005).

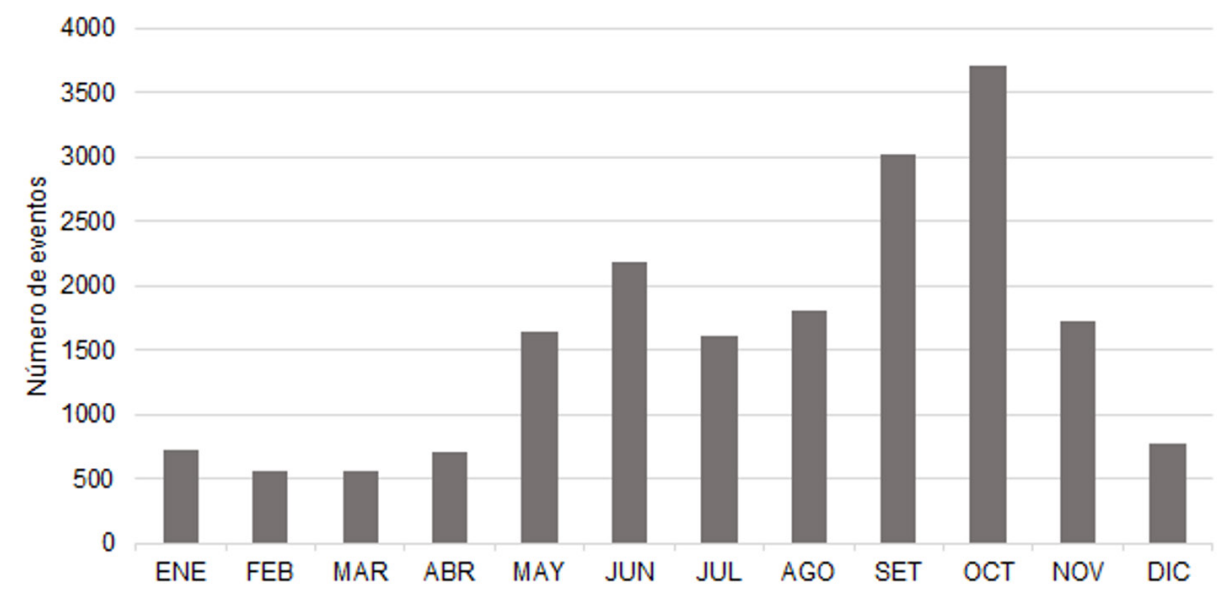

Figura 8. Número de eventos registrados por mes, Costa Rica, periodo 1970-2020 Fuente: Autores, 2022, con datos de UNDRR (2021b)

Al realizar un filtro a nivel anual de la cantidad de eventos registrados en la base de datos durante el periodo de estudio, se obtuvo que el quinquenio del 2007 al 2011 (a excepción del 2009), es el que presenta la mayor cantidad de eventos registrados de manera consecutiva en la base de datos, siendo el 2007 el año que encabeza el registro con 1.560 fichas generadas (ver Figura 9), de las cuales el $55 \%$ corresponde a eventos de inundación y el $30 \%$ de deslizamiento ligado a condiciones atmosféricas; este mismo patrón lo presentan el 2008 y 2010 como segundo y tercer año con mayor cantidad de fichas registradas, así como el quinquenio 2007-2011, siendo que entre el 80 y $85 \%$ de los eventos registrados en estos son de tipo hidrometeorológico.

Al analizar las causas asociadas a los eventos registrados, sobresalen las condiciones atmosféricas, lluvias y desbordamiento como las mayoritarias, lo que se relaciona con eventos de la fase fría del fenómeno El Niño-Oscilación del Sur (ENOS), estando La Niña presente en estos años de análisis (NOAA, 2021; Quesada, 2005; Ramírez et al., 2017), siendo que el efecto de La Niña en Costa Rica se relaciona con promedios de precipitación superiores (Quesada, 2005; Waylen y Quesada, 2002). Incluso, los eventos La Niña de los años 2007-2008 y 2010-2011 fueron clasificados de acuerdo con el Índice Oceánico de El Niño (ONI) como episodios fuertes de la fase fría (La Niña) (NOAA, 2021).

En cuanto a cantidad de personas fallecidas por año, se destaca el 2009 como el que posee la mayor cantidad de muertes ligadas a desastres (93), principalmente asociados a sismos, como el terremoto de Cinchona ocurrido en el país el 8 de enero de 2009, con una magnitud de 6,2 Mw a $6 \mathrm{~km}$ de profundidad, que cobró la vida de 25 personas y afectó infraestructuras tales como: puentes, caminos, viviendas, iglesias, líneas de transmisión eléctrica y represas hidroeléctricas (Barrantes et al., 2013). 
Por su parte, los años 2010, 2008 y 2011 con 91, 75 y 73 personas fallecidas, se relacionan con eventos de deslizamiento, ligados a condiciones atmosféricas, lo cual concuerda con los años de mayor registro en la base de datos.

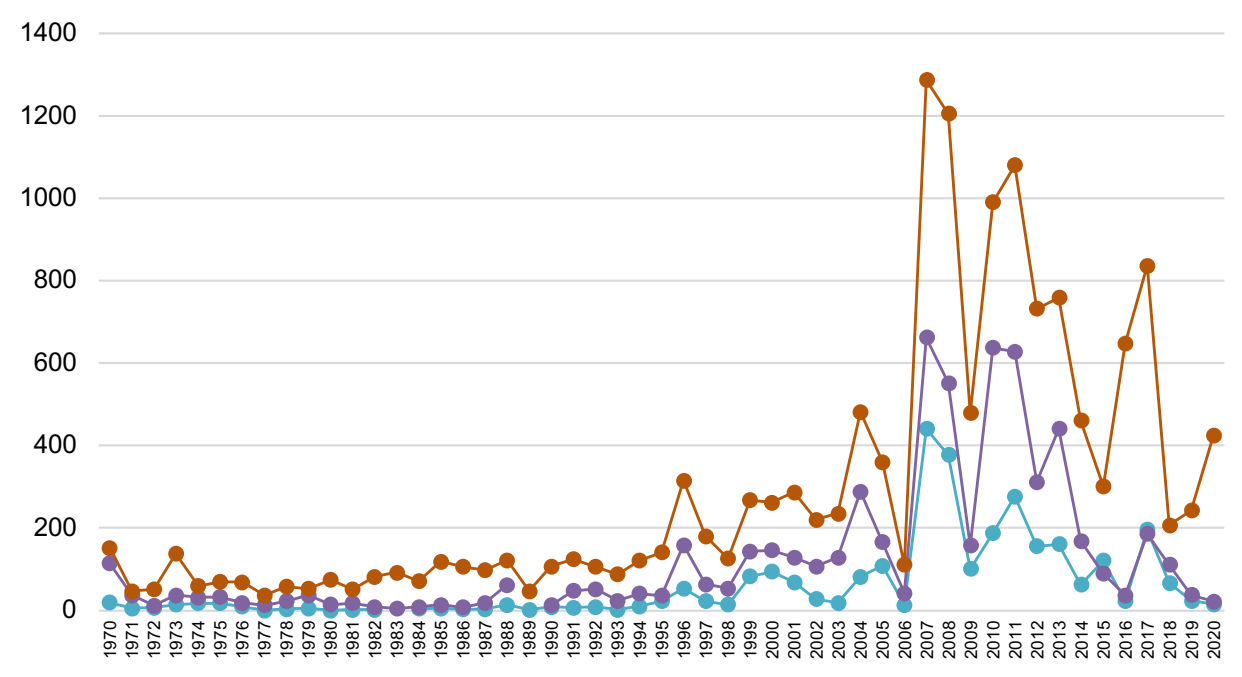

$\multimap$ Deslizamiento $\multimap$ Inundacion $\longrightarrow$ Total de eventos

Figura 9. Número total de eventos registrados, deslizamientos e inundaciones en Costa Rica por año (1970-2020) Fuente: Autores, 2022, con datos de UNDRR (2021b)

Como parte del análisis de las series temporales, se realizaron un conjunto de pruebas de tendencia para diversas variables que están incluidas en la base de datos analizada, para el periodo de 1970 al 2020. Específicamente se estudió el comportamiento de las tendencias del total de los eventos registrados, así como de los deslizamientos, las inundaciones y el número de muertes registrados por año según todos los eventos contabilizados.

Las pruebas Mann Kendall para las series temporales del total de eventos, de deslizamientos y de inundaciones (1970-2020) arrojan valores p menores a 0,05 (2.22e-16, 1.1921e-07 y 1.3113e06 respectivamente), por tanto, hay suficiente evidencia estadística para rechazar la hipótesis nula de la prueba en los 3 casos, por lo que existe una tendencia en los datos. Al analizar la Figura 9 , se podría sugerir que la tendencia es hacia el aumento de cada uno de los eventos específicos analizados (deslizamiento e inundaciones) y por lo tanto de la totalidad de los eventos registrados anualmente. Lo anterior, también sucedió para la serie de muertes, donde la prueba realizada reportó un valor p igual a 2.7418e-06 (ver Figura 5).

Por otro lado, al analizar las medias por década del total de los desastres, de deslizamientos, de inundaciones y de muertes (Tabla 1), se verifica la tendencia en el aumento de estos, lo cual es coincidente con los resultados expuestos previamente. Sin embargo, cabe destacar que, posiblemente conforme se ha identificado la necesidad del registro de estos eventos, las autoridades encargadas del relevamiento de datos estén haciendo mayores esfuerzos por obtener la información, lo cual automáticamente aumentaría el reporte de datos y así podría explicarse la tendencia de aumento de eventos, deslizamientos, inundaciones y muertes, lo cual también puede estar acompañado del cambio climático.

\begin{tabular}{rcccc} 
Década & Total de desastres & Deslizamiento & Inundaciones & Muertes \\
\hline $\mathbf{1 9 7 0}$ & 73,5 & 10,3 & 35,8 & 6,6 \\
\hline $\mathbf{1 9 8 0}$ & 86,3 & 4,33 & 17,7 & 7,4 \\
\hline $\mathbf{1 9 9 0}$ & 157,7 & 23,6 & 63,5 & 21,1 \\
\hline $\mathbf{2 0 0 0}$ & 492,8 & 133,6 & 238,0 & 57,0 \\
\hline $\mathbf{2 0 1 0}$ & 625,7 & 127,6 & 265,9 & 43,5 \\
\hline
\end{tabular}

Tabla 1. Promedios de total de desastres, deslizamientos, inundaciones y muertes por década, período 1970-2020 Fuente: Autores, 2022, con datos de UNDRR (2021b) 
Lo anterior, es consistente con lo reportado por UNDRR (2021a), cuando indica que este aumento no solo se explica debido al mejoramiento en el registro de la información, sino principalmente al incremento en la cantidad de eventos, la vulnerabilidad y la exposición de personas y bienes. Por otro lado, el aumento de la población y la urbanización sin planificación, son dos factores directamente relacionados con este incremento. De acuerdo con Wisner et al. (2003), la ocurrencia de los desastres no se debe exclusivamente a los eventos naturales que los causan, sino que también son producto del entorno social, político y económico que estructuran la vida de distintos grupos de personas.

Por ello, Dutta et al. (2001) señalan que la estimación de pérdidas económicas por amenazas naturales futuras es esencial para la preparación ante desastres, ya que es la base para la toma de decisiones a nivel local, regional y nacional y proporcionan un instrumento eficaz para la planificación, zonificación, regulaciones de desarrollo y políticas hacia la reducción del riesgo de desastres.

Por otro lado, en cuanto a impactos económicos recientes, la Unidad de Desarrollo Estratégico de la CNE (CNE, 2020), destacó que las pérdidas económicas por eventos de desastre entre 1991 y 2020 es de $\phi 2,083,085,867,152.50$ (Tabla 2), donde los eventos de tipo hidrometeorológico son los que han generado la mayor cantidad de pérdidas económicas durante los últimos 30 años, representando el $63 \%$ de las pérdidas.

\begin{tabular}{rcc} 
Tipo de evento & Pérdidas en millones de colones & Porcentaje \\
\hline Antrópico & $2,507,719,000.00$ & $0,12 \%$ \\
\hline Biológico & $413,935,469,609.87$ & $19,87 \%$ \\
\hline Geológico & $349,611,545,905.44$ & $16,78 \%$ \\
\hline Hidrometeorológico & $1,317,031,132,637.19$ & $63,23 \%$ \\
\hline Total general & $2,083,085,867,152.50$ & $100 \%$ \\
\hline
\end{tabular}

Tabla 2. Pérdidas en millones de colones por eventos de desastre en Costa Rica. 1991-2020 Fuente: CNE (2020)

\section{IMPORTANCIA DEL USO DE LA BASE DE DATOS DI-COSTA RICA}

DesInventar es utilizado por personas investigadoras, Instituciones de Educación Superior y centros de investigación y extensión universitaria para la generación de publicaciones científicas, líneas de base y contextualización territorial. Organismos internacionales, regionales y nacionales han publicado informes tomando como base el inventario que contiene la base de datos DI-Costa Rica, por ejemplo, UNDRR la utilizó en The UN Global Assessment Report on Disaster Risk Reduction (GAR) desde su primera edición hasta la edición del 2015, su última versión (2019) inició con el uso de DesInventar-Sendai, plataforma a la cual DI-Costa Rica se encuentra en proceso de migración. A nivel regional, se ha utilizado para informes del Estado de la región desde el 2008 y para la Evaluación Probabilista de Riesgos en Centroamérica (CAPRA), mientras que a nivel nacional es utilizado por el Programa Estado de la Nación del Consejo Nacional de Rectores (CONARE) desde el 2002, para el Informe Estado de la Nación de cada año. Reiteradas veces, ha servido como herramienta para sistematizar las pérdidas y daños de desastres de gran magnitud y generar los reportes e informes que fundamentarán la solicitud de ayuda humanitaria por parte de los gobiernos en turno.

Por otro lado, investigadores desde el área histórica han destacado la importancia de la herramienta como un "repositorio estadístico" para las investigaciones sobre gestión del riesgo de desastres con perspectiva centroamericana (Zúñiga et al., 2019).

Las investigaciones de Campos-Durán y Quesada-Román (2017), así como Pérez-Briceño et al. (2016), visualizan la importancia de la base de datos para análisis de riesgos intensivos y extensivos en el primer caso, y del impacto de eventos hidrometeorológicos en el segundo, no solo a nivel nacional, si no con un enfoque centroamericano. Además, sobresalen investigaciones a nivel local con uso de la plataforma DI-Costa Rica para realizar análisis de indicadores de riesgo como los realizados por Brenes-Maykall y Orozco-Montoya (2018) y Barrantes et al. (2017).

El uso de DI-Costa Rica para investigaciones sobre el impacto de eventos hidrometeorológicos en Costa Rica evidencia su veracidad y utilidad para la generación de conocimiento científico en 
el país y la región centroamericana, a través del análisis de efectos producidos por desastres y de datos (Alfaro y Quesada, 2010; Quesada-Hernández et al., 2020; Quesada-Román et al., 2020).

\section{LIMITANTES Y RETOS DEL INVENTARIO HISTÓRICO DE DESASTRES DI-COSTA RICA}

Ante el hecho que la CNE decide desarrollar sus propios mecanismos para registrar las pérdidas por desastre, la base de datos DI-Costa Rica quedó sin un respaldo oficial por parte de la entidad rectora en gestión del riesgo en el país, institución que a su vez lidera el Sistema Nacional de Gestión del Riesgo (SNGR) de Costa Rica. Lo anterior, limitó de forma temprana la posibilidad de establecer convenios y formalizar la relación para definir procedimientos de operativización de procesos estratégicos como el acceso y uso de la información generada por la CNE para su inclusión en la base de datos. Lo anterior, no solo ha afectado el acceso y uso de la información que, al quedar delimitado por las voluntades personales, perjudica cualquier ejercicio investigativo que pretenda brindar información confiable, si no que ha incidido en la confianza que la persona usuaria de DI-Costa Rica debería tener en la base de datos, lo cual se contrarresta por la credibilidad de las universidades públicas en su quehacer sustantivo, en este caso, la UNA. Por lo tanto, se reconoce como un reto y tarea pendiente la Institucionalización de este reconocimiento formal por parte de la CNE.

En sus inicios, Deslnventar usaba como principal fuente de información la prensa (fuentes hemerográficas). Una vez que los distintos sectores empezaron a generar informes de situación de pérdidas y daños, la alimentación de la base de datos utilizando únicamente la prensa como fuente de información se convirtió en una limitante, por cuanto, sectores relevantes como: transporte, energía, agua y saneamiento, educación, salud, municipal y agroalimentario, producían información relevante de daños y pérdidas afines a la ficha del inventario de eventos de DesInventar. Es así como se generaron vínculos con las instituciones para formalizar el acceso y uso de la información, y de esa forma se diversificaron las fuentes de información con las que el inventario de Costa Rica se alimenta. Esto ha posibilitado que la base de datos se nutra de la información generada por los mismos sectores estratégicos impactados por los desastres.

Dentro del conjunto de variables que contempla la ficha de registro de la base de datos DesInventar, el costo de las pérdidas sigue siendo una de las variables con mayores retos en lo que corresponde a que el dato se haya contabilizado. Desde sus inicios, ha sido una variable con escasa disponibilidad de información, ya que la fuente consultada, si bien en algunas ocasiones no posee el dato disponible, en otras el formato de entrega no se ajusta a lo requerido en la base de datos en cuanto a unidad de medida o escala territorial. Aunque los instrumentos de registro y las fórmulas de cálculo han sido discutidas y analizadas en conjunto con la CNE y grupos de personas expertas en la temática de bases de datos y gestión de la información en gestión del riesgo, sigue siendo un reto la normalización y ajuste de estos instrumentos. A tal efecto, sigue siendo un reto y prioridad que seguimos enfrentando como SNGR dada la relevancia que representa el tener acceso y uso de la información en la toma de decisiones.

Si bien DI-Costa Rica es utilizado por múltiples sectores y actores como un sistema de información sobre pérdidas por desastres, sostener su actualización es un proceso que ha enfrentado distintos obstáculos. Actualmente, los recortes presupuestarios al sistema de educación superior pública costarricense atentan contra la acción sustantiva universitaria, en este caso, en el mantenimiento de la base de datos DI-Costa Rica.

La migración de la base DI-Costa Rica a DesInventar-Sendai ha sido un proceso arduo de adaptación en el acceso y manipulación de la base de datos, ya que dicho acontecimiento, sin previa planificación y en un plazo muy corto, afectó el proceso de alimentación de la base de datos y el acceso a la plataforma por parte de las personas usuarias.

Sigue siendo un reto que los gobiernos locales se apropien de la herramienta, para que al igual que la Municipalidad de San José (municipio del cantón capitalino), generen su propio inventario de pérdidas por desastres según tipología de interés, con la finalidad de posicionar desde la gestión municipal ordinaria, el análisis de escenarios de desastres, pérdidas y patrones de riesgo y vulnerabilidad, así como la intervención en la planificación del desarrollo local territorial y socioeconómico, fortaleciendo la gobernabilidad del riesgo de desastre. 


\section{CONCLUSIONES}

La base DI-Costa Rica señala en sus registros que, durante la última mitad de siglo, los eventos de tipo hidrometeorológico representan los de mayor ocurrencia en el país, siendo el $80 \%$ de los eventos registrados en la base de datos de desastres, la cual cuenta con 19.016 registros de eventos ocurridos en Costa Rica en el período 1970-2020. Estos eventos se relacionan con eventos de inundación, lluvias, deslizamientos causados por condiciones atmosféricas, avenida torrencial, tempestad, vendaval, sequía y marejada.

Entre 1970 y el 2020, se han registrado 1.555 personas fallecidas por desastres en Costa Rica según DesInventar, donde el $51 \%$ (787) se dieron por corrientes de resaca, el 32\% (503) por eventos hidrometeorológicos, el 11\% (163) por eventos de tipo humano-tecnológico, el $5 \%$ (83) por eventos geológicos y el restante $1 \%$ se dio por epidemias, donde sobresalen los casos causados por la transmisión del virus SARS- CoV-2 durante el 2020.

La relación entre la concentración de fichas a nivel distrital y el IDS destaca que los distritos clasificados con bajo y muy bajo desarrollo relativo concentran el $40 \%$ de fichas registradas $(29 \%$ y $11 \%$ respectivamente), entre ellos destacan Parrita, Corredor, Guaycará, Golfito y Siquirres, ubicados los 4 primeros en regiones costeras del Pacífico Central y sur del país.

De acuerdo con la Unidad de Desarrollo Estratégico de la CNE, las pérdidas económicas por eventos de desastre entre 1991 y 2020 es de $\not 2,083,085,867,152.50$, donde los eventos de tipo hidrometeorológico son los que han generado la mayor cantidad de pérdidas económicas durante los últimos 30 años, representando el 63\%.

Del análisis gráfico y las pruebas estadísticas de tendencia alrededor de las series de tiempo de conteos de totalidad de eventos ocurridos, inundaciones y deslizamientos por año de 1970 al 2020, se concluye que este tipo de eventos van aumentando en el Costa Rica. Lo anterior, se debe a que se están haciendo conteos más sistemáticos de los desastres, así como del aumento de las catástrofes registradas a nivel mundial como consecuencia del cambio climático. En otras palabras, como era esperable, Costa Rica mantiene la misma tendencia de aumento del resto del mundo en el aumento de eventos hidrometeorológicos que ponen en riesgo a su población.

Actualmente, Deslnventar es el único registro histórico de pérdidas de pequeños, medianos y grandes desastres que acumula 51 años de información (1970-2020) para Costa Rica, que ha procurado atender las necesidades de investigación y las recomendaciones producto de las evaluaciones técnicas realizadas por la Corporación OSSO y por diferentes instituciones y personas usuarias, con el fin de mantener su calidad y confiabilidad.

Desinventar es utilizado por la UNDRR como la única base de datos con información que permite la medición de los indicadores de las metas del Marco de Acción de Sendai, lo que consolida los datos anuales que se comunican a través del Monitor.

La actual coyuntura donde DesInventar ha iniciado su migración hacia la nueva plataforma DesInventar-Sendai, desde donde se gestionará la información y los datos sobre pérdidas por desastre con el fin de reportar los avances nacionales de las 7 metas del Marco de Acción de Sendai, ofrece la oportunidad de consolidar los esfuerzos y recursos cada vez más limitados de la academia y los de otros miembros del Sistema Nacional de Gestión del Riesgo bajo el liderazgo de la CNE en una búsqueda por robustecer un inventario de pérdidas por desastres con 51 años de registro.

DesInventar se ha convertido en una herramienta eficaz y actualizada que contabiliza los efectos de desastres a grande, mediana y pequeña escala, tomando como punto de partida lo cotidiano, de forma que cualquier tipo de evento ocurrido en el país sea registrado. Es de esta forma como la base de datos representa un instrumento confiable de información, validada y comparada con información oficial, siendo pertinente para investigaciones científicas, comparación de efectos y tendencias a nivel espacial y temporal, que, al ser de libre acceso, permite información accesible y disponible para el análisis social y territorial, la planificación del territorio y la toma de decisiones, y planificar el desarrollo local y su inversión.

Una limitante identificada es el registro de localización (coordenadas geográficas) de los incidentes ya que, aunque en cada ficha de registro pueden introducirse los datos de latitud y longitud, la mayoría de las fuentes de información han obviado dichos datos, por lo que no se ha logrado que la base de datos posea este nivel de detalle. 


\section{REFERENCIAS}

Alfaro, E.J., \& Quesada, A. (2010). Ocurrencia de ciclones tropicales en el Mar Caribe y sus impactos sobre Centroamérica. Intersedes, 11(22), 136-153.

Aon. (2021). Annual Report 2020: Weather, Climate \& Catastrophe Insight. Aon. http:// thoughtleadership.aon.com/Documents/20210125-if-annual-cat-report.pdf

Arozarena-Llopis, I., \& Gutiérrez-Echevarría, A. (2016). Las corrientes de resaca en las playas de Costa Rica: Un problema de primer orden. Universidad En Diálogo: Revista De Extensión, 5(2), 21-37. https://www.revistas.una.ac.cr/index.php/dialogo/article/view/8427

Banco Mundial. (2021, 19 de octubre). Costa Rica: Panorama general. Banco Mundial. https://www. bancomundial.org/es/country/costarica/overview\#1

Barrantes-Castillo, G., Jiménez-Campos, C., \& Ocón-García, M.J. (2013). Deslizamientos provocados por el terremoto de Cinchona de 2009, Costa Rica. Revista Geográfica De América Central, 2(51), 89-100. https://www.revistas.una.ac.cr/index.php/geografica/article/view/599o

Barrantes-Castillo, G., Quesada-Román, A., Campos-Durán, D., \& Padilla-Umaña, K. (2017). Indicador de afectación por eventos naturales en el cantón de Alajuela, y su relación con la vulnerabilidad comunal. Revista Geográfica de América Central, 3(59), 159-196. https://doi.org/10.15359/rgac.3-59-6

Brenes-Maykall, A. \& Orozco-Montoya, R. (2018). Causas subyacentes del impacto de la tormenta tropical Nate en el Sur-sur de Costa Rica. Aceptado para IV Congreso Nacional de Gestión del Riesgo de Desastres y Adaptación al Cambio Climático. San José, Costa Rica.

Brenes, A. (2020). Gestión del riesgo en Costa Rica. Ponencia preparada para el Informe Estado de la Nación 2020. PEN.

Brenes-Maykall, A., \& Orozco-Montoya, R.A. (2021). Gestión del riesgo en Costa Rica. Ponencia preparada para el Informe Estado de la Nación 2021. San José: PEN. (En prensa).

Brighton, B., Sherker, S., Brander, R., Thompson, M., \& Bradstreet, A. (2013). Rip current related drowning deaths and rescues in Australia 2004-201. Natural Hazards and Earth System Sciences, 13, 1069-1075.

Campos-Durán, D., \& Quesada-Román, A. (2017). Riesgos Intensivos y Extensivos en América Central entre 1990 y 2015. Anuário do Instituto de Geociências, 40(2), p. 234-249. http://dx.doi. org/10.11137/2017_2_234_249

Campos-Durán, D., Quintero-Quintero, R., \& Abarca-Rojas, T. (2021). Terremoto del Valle de La Estrella: análisis sísmico, cascada de desastres y pérdidas económicas en valor presente (2020). Revista Geológica de América Central, 65, 1-23. https://revistas.ucr.ac.cr/index.php/geologica/article/ view/47079

CNE. (2020). Pérdidas en millones de colones 1991-2020. Unidad de Desarrollo Estratégico.

CRED. (2018). EM-DAT The International Disasters Database. CRED-UCL. https://www.emdat.be

Decreto Ejecutivo $\mathrm{N}^{\circ}$ 40184-MGP. (2017). División Territorial Administrativa de la República de Costa Rica, publicado en el Alcance $\mathrm{N}^{\circ} 52$ a La Gaceta $\mathrm{N}^{\circ} 48$ del 8 de marzo de 2017.

Dutta, D., Herath, S., \& Musiake, K. (2001). Direct flood damage modeling towards urban flood risk management. ICUS/INCEDE Report 1. Bangkok, Tailandia, Urban Safety Engineering. P. 127-143.

Gensini, V., \& Ashley, W. (2010). An examination of rip current fatalities in the United States. Natural Hazards, 54, 159-75.

Hidalgo, H.G., Alfaro, E.J., Hernández-Castro, F., Pérez-Briceño, P.M. (2020). Identification of Tropical Cyclones' Critical Positions Associated with Extreme Precipitation Events in Central America. Atmosphere, 11, 1123. https://doi.org/10.3390/atmos11101123

Irish Red Cross. (2018). Disaster Displacement Information Sheet. Centre for Criminal Justice and Human Rights. IRC. https://reliefweb.int/sites/reliefweb.int/files/resources/IDL-Information-SheetNo.5-Disaster-Displacement-February-2018.pdf

Kendall, M.G. (1975). Rank correlation methods. Charles Griffin.

La Red. (1992). Agenda de Investigación y Constitución Orgánica. La Red. https://www.desenredando. org/public/libros/1992/agenda/

Lavell, C., \& Lavell, A. (2010). Informe Técnico sobre Desastres en la Región: 1999-2009. Riesgo, Desastre y Gestión del Riesgo en Centroamérica: 1999-2010. Ponencia preparada para el Cuarto Informe Estado de la Región 2010. San José: PEN. 
Lizano, O. (2012). Las corrientes de resaca, el riesgo y las muertes por sumersión en las playas de Costa Rica. En torno a la prevención, (8), 23-27.

Maldonado, T., Alfaro, E.J., \& Hidalgo, H.G. (2018). A review of the main drivers and variability of Central America's Climate and seasonal forecast systems. Revista de Biología Tropical, 66(1). http:// dx.doi.org/10.15517/RBT.V66I1.33294

Mann, H.B. (1945). Nonparametric tests against trend. Econometrica 13, 245-259.

Mideplan. (2017). Índice de desarrollo social 2017. Mideplan.

Morales, L.D. (1994). Daños causados por el Terremoto de Limón: pérdidas y medidas de mitigación. Revista Geológica de América Central, 17, 201-210. http://dx.doi.org/10.15517/RGAC.Volo.13455

NOAA. (2021). Índice ONI. NOAA. https://origin.cpc.ncep.noaa.gov/products/analysis_monitoring/ ensostuff/ONI_v5.php

OCHA. (2020). Global Humanitarian Overview 2019. OCHA. https://www.unocha.org/sites/unocha/ files/GHO2019.pdf

ONU. (1989). Decenio Internacional para la Reducción de los Desastres Naturales. Resol.44/236. 85ํㅡㄹ sesión plenaria. ONU.

Pérez-Briceño, P., Alfaro, E., Hidalgo, H., \& Jiménez, F. (2016). Distribución espacial de impactos de eventos hidrometeorológicos en América Central. Revista de Climatología, 16, 63-75.

Quesada, M. (2005). Variabilidad de la precipitación anual asociada con los eventos El Niño y La Niña en las ciudades de Naranjo, Palmares y San Ramón, Costa Rica. Polígonos. Revista de Geografía, 15, 89-103. http://dx.doi.org/10.18002/pol.voi15.428

Quesada-Hernández, L.E., Hidalgo, H., \& Alfaro, E. (2020). Asociación entre algunos índices de sequía e impactos socio-productivos en el Pacífico Norte de Costa Rica. Revista De Ciencias Ambientales, 54(1), 16-32. https://doi.org/10.15359/rca.54-1.2

Quesada-Román, A., Villalobos-Portilla., E \& Campos-Durán, D. (2020). Hydrometeorological disasters in urban areas of Costa Rica, Central America. Environmental Hazards, 20(3), 264-278. https://doi.or $\mathrm{g} / 10.1080 / 17477891.2020 .1791034$

Ramírez, A., Chamizo, H., \& Fallas, J. (2017). El Fenómeno ENOS y el dengue, Regiones Pacífico Central y Huetar Atlántico, Costa Rica, 1990 a 2011. Población y Salud en Mesoamérica, 15(1), 1-18. https://doi. org/10.15517/psm.v15i1.26189

Retana, J. (2012). Eventos hidrometeorológicos extremos lluviosos en Costa Rica desde la perspectiva de la adaptación al cambio en el clima. Revista de Ciencias Ambientales, 44(1), 5-16. https://doi. org/10.15359/rca.44-2.1

Silva, D.G. (2007). Evolução Paleoambiental dos Depósitos de Tanques em Fazenda Nova, Município de Brejo da Madre de Deus - Pernambuco (Tesis de Maestría). Universidade Federal de Pernambuco UFPE.

Sistema Nacional de Monitoreo de Tsunamis SINAMOT. (2021). Antecedentes. Universidad Nacional de Costa Rica. https://www.sinamot.una.ac.cr/

Taylor, M.A., \& Alfaro, E.J. (2005). Central America and the Caribbean, climate of. In Encyclopedia of world climatology (pp. 183-189). Springer Netherlands.

UNDRR. (2017). Guía de orientación técnica para el monitoreo y la presentación de informes sobre los avances para alcanzar las metas globales del Marco de Sendai para la Reducción del Riesgo de Desastres. UNDRR. https://www.preventionweb.net/drr-framework/open-ended-working-group

UNDRR. (2019). Global Assessment Report on Disaster Risk Reduction 2019. UNDRR.

UNDRR. (2021a). Informe de evaluación regional sobre el riesgo de desastres en América Latina y el Caribe. UNDRR.

UNDRR. (2021b). Desinventar Project. 2021. Plataforma Desinventar Sendai. UNDRR. https:// db.desinventar.org/DesInventar/profiletab.jsp? countrycode $=$ cria\&continue $=y$

Waylen, P., \& Quesada, M. (2002). The effect of Atlantic and Pacific Sea surface temperature on the Mid-Summer drought of Costa Rica. Cuadernos de Investigación Geográfica, 27, 193-205. https://doi. $\operatorname{org} / 10.18172 /$ cig.1123

Wisner, B., Blaikie, P., Cannon, T., \& Davis, I. (2003). At Risk: natural hazards, people's vulnerability and disasters (2nd Ed.). Routledge. 
Yu, J.-Y., \& Kao, H.-Y. (2007). Decadal changes of ENSO persistence barrier in SST and ocean heat content indices: 1958-2001. Journal of Geophysical Research JGR: Atmospheres, 112, D13106. http:// doi.org/10.1029/2006JDoo7654

Zúñiga Arias, Y., Granados Porras, R., \& Coto Cedeño, W. (2019). Fuentes estadísticas para el estudio de la gestión del riesgo de desastres en Centroamérica. La base de datos DESINVENTAR y sus aportes para la investigación histórica. Revista de Historia, (8o), 153-17o. https://doi.org/10.15359/rh.80.6 